\title{
Desigualdade e seletividade social das medidas de contenção da Covid-19 na periferia de Curitiba
}

\author{
Inequality and social selectivity of Covid-19 containment measures on the outskirts of Curitiba
}

\author{
Marcelo Nogueira de Souza ${ }^{1}$
}

\begin{abstract}
Resumo
$\mathrm{O}$ artigo analisa alguns aspectos da desigualdade na cidade de Curitiba e seus desdobramentos diante da pandemia de Covid-19. A análise comparativa se baseia no Índice de Bem-estar Urbano (Ibeu), desenvolvido pelo Observatório das Metrópoles; no Índice de Vulnerabilidade das Áreas de Abrangência das Unidades Municipais de Saúde (Ivab), desenvolvido pelo Ipardes; além de dados do Ipea (2020), que constataram que a região central de Curitiba segue o mesmo padrão observado em outras cidades, ou seja, concentra um maior número de hospitais com condições para atender a pacientes em estado grave com suspeita de Covid-19, revelando, assim, a seletividade social das medidas de higiene e isolamento recomendadas pelas autoridades.
\end{abstract}

Palavras-chave: Desigualdade social. Segregação espacial. Covid-19.

\begin{abstract}
The article analyzes some aspects of inequality in the city of Curitiba and its developments in the face of the Covid-19 pandemic. The comparative analysis is based on the Urban Wellbeing Index (Ibeu), developed by the Observatório das Metrópoles; on the Vulnerability Index of the Areas of Coverage of Municipal Health Units (Ivab), developed by Ipardes; in addition to data from Ipea (2020), who found that the central region of Curitiba follows the same pattern observed in other cities, that is, it concentrates a greater number of hospitals with conditions to attend to seriously ill patients with suspected Covid-19, thus revealing the selectivity hygiene and isolation measures recommended by the authorities.
\end{abstract}

Keywords: Social inequality. Spatial segregation. Covid-19.

\section{Introdução}

A análise da literatura a respeito de estudos realizados no campo da sociologia urbana revela que tem crescido o número de pesquisas que associam a organização social do território às inúmeras formas de desigualdade. Tais estudos adquirem especial relevância diante da atual pandemia de

\footnotetext{
${ }^{1}$ Doutor em Sociologia (UFPR). Mestre em Políticas Educacionais (UFPR). Bacharel em Ciências Sociais (UFPR). Pós-doutorando em Sociologia pela UFPR. Pesquisador do grupo de pesquisa "Políticas sociais: análise comparada das experiências brasileiras", do "Programa de Desenvolvimento Urbano e Regional - PDUR" e do projeto "As metrópoles e o direito à cidade: conhecimento, inovação e ação para o desenvolvimento urbano", vinculado ao Observatório das Metrópoles - Núcleo Curitiba. E-mail: 666noma@gmail.com.
} 
Covid $-19^{2}$ e dos esforços das autoridades sanitárias para evitar o aumento no número de casos da doença em diversos países do mundo. Ações que, no entanto, têm se mostrado problemáticas, especialmente em países marcados por desigualdades históricas, como o Brasil, que privam os grupos populacionais mais vulneráveis do acesso a bens e serviços públicos considerados essenciais no enfrentamento da pandemia.

Importante ressaltar que, atualmente, a sociologia urbana tem lidado com diferentes formas de segregação socioespacial que caracterizam as grandes cidades brasileiras. Num plano macro, observa-se a manutenção do padrão centro-periferia, que concentra nas periferias a maioria dos pobres e nas áreas centrais os grupos de média e alta rendas. Nesse sentido, a cidade de Curitiba pode ser analisada de acordo com esse padrão, na qual a segregação é medida em grande escala (centro e periferia), restringindo o acesso de grupos sociais vulneráveis (em geral, moradores da região periférica) ao conjunto de serviços públicos providos pelo Estado, o que tem causado preocupação nas autoridades sanitárias de todo mundo, uma vez que essa desigualdade pode ser o gatilho de uma transmissão descontrolada caso não sejam desenvolvidas ações com foco nessas áreas com alto índice de vulnerabilidade social.

O objetivo do presente estudo, que apresenta os resultados parciais da pesquisa de pós-doutorado em Sociologia do autor, é conhecer alguns aspectos da desigualdade na cidade de Curitiba - manifestada através de indicadores como renda, habitação, saneamento, coleta de lixo, acesso a serviços e bens públicos e, principalmente, através da política de mobilidade urbana do município - e que têm importantes desdobramentos diante da pandemia de Covid-19. O estudo será feito através de uma análise comparativa com base no Índice de Bem-estar Urbano (Ibeu), desenvolvido pelo Observatório das Metrópoles, e o Índice de Vulnerabilidade das Áreas de Abrangência das Unidades Municipais de Saúde (Ivab), desenvolvido pelo Ipardes, além de algumas reflexões relacionadas à nota técnica do Ipea (2020) que corrobora nossa preocupação ao constatar que a região central de Curitiba segue o mesmo padrão observado em outras cidades, ou seja, concentra um maior número de hospitais com condições para atender a pacientes em estado grave com suspeita de Covid-19, revelando a seletividade social das medidas de higiene e isolamento recomendadas pelas autoridades.

Na primeira seção - Centro e periferia de Curitiba: interpretações sobre a desigualdade na "cidade modelo" - através de uma revisão bibliográfica das obras de alguns dos principais pesquisadores da sociologia urbana, buscamos compreender os impactos da segregação espacial na

\footnotetext{
${ }^{2}$ Doença respiratória aguda causada pelo coronavírus da síndrome respiratória aguda grave 2 (SARS-CoV-2), identificada pela primeira vez em Wuhan, na província de Hubei, República Popular da China, em 1 de dezembro de 2019.
} 
região de Curitiba que é marcada pela forma mais tradicional da segregação espacial: a oposição centro x periferia, em que os mais abastados situam-se próximos ao centro e os desfavorecidos economicamente habitam as franjas das cidades, distantes dos equipamentos e da infraestrutura.

Na segunda seção - intitulada "Centro e periferia de Curitiba vistos pelo índice de Bem-estar Urbano (Ibeu) e pela taxa de mobilidade urbana" - analisamos como este processo de segregação espacial (centro-periferia) desencadeia mecanismos que restringem o acesso de moradores da região periférica ao conjunto mais amplo de oportunidades providas pelo Estado.

$\mathrm{Na}$ terceira e última seção - "Estratégias de enfrentamento da Covid-19: impactos da segregação espacial na periferia de Curitiba" - analisamos como a acertada estratégia da Secretaria Municipal da Saúde (SMS) de priorizar as Equipes de Estratégia Saúde da Família (ESF) para as áreas mais vulneráveis pode - em um eventual, e previsível, aumento do número de casos de Covid-19 nestas periferias - ser afetada pela mobilidade urbana desigual, uma vez que estes bairros periféricos estão distantes dos estabelecimentos com capacidade para atender os casos mais graves de Covid-19.

\section{Centro e periferia de Curitiba: interpretações sobre a desigualdade na "cidade modelo"}

Curitiba é conhecida mundo afora como "a cidade modelo". De fato, em 2012, de acordo com o IBGE, Curitiba ocupava a $10^{\mathrm{a}}$ posição entre os 5.565 municípios brasileiros segundo o Índice de Desenvolvimento Humano Municipal $\left(\mathrm{IDHM}^{3}\right)$, que abarca três dimensões: longevidade, educação e renda. Entretanto, dois anos antes, em 2010, era divulgado o relatório do Fórum Urbano Mundial da ONU e Curitiba figurava entre as mais desiguais do mundo, aparecendo em $17^{\circ}$ lugar no ranking global, sendo a quinta cidade mais desigual da América Latina. Ou seja, Curitiba é também reconhecida internacionalmente pela desigualdade social.

O contraste da "cidade modelo", que é uma das mais desiguais do mundo, tem suas raízes no planejamento urbano excludente e pode ser entendido através da análise do Plano Diretor posto em prática, principalmente através das políticas habitacionais, na década de 1970. De acordo com Albuquerque (2007):

[...] o elemento mais explícito da política habitacional de Curitiba foi a periferização da população de baixa renda '[...] a produção habitacional da 'cidade modelo' empurrou os pobres de Curitiba para as bordas do Município”. (ALBUQUERQUE, 2007, p. 113).

\footnotetext{
${ }^{3}$ O IDHM brasileiro considera as mesmas três dimensões do IDH Global - longevidade, educação e renda, mas vai além: adequa a metodologia global ao contexto brasileiro e à disponibilidade de indicadores nacionais. Embora meçam os mesmos fenômenos, os indicadores levados em conta no IDHM são mais adequados para avaliar o desenvolvimento dos municípios e regiões metropolitanas brasileiras.
} 
Ainda, de acordo com Lojkine (1997), a forma mais tradicional da segregação espacial é a oposição centro x periferia, em que os mais abastados situam-se próximos ao centro e os desfavorecidos economicamente habitam as franjas das cidades, distantes dos equipamentos e infraestrutura. Curitiba segue este padrão. Os bairros periféricos aqui analisados situam-se no extremo sul do município, bastante afastados dos bairros da região central.

De acordo com Carvalho e Sugai (2013), as ações e repercussões do Plano Diretor da cidade de Curitiba - elaborado durante a década de 1970 - assim como toda a dinâmica da "transformação" do espaço e da imagem da cidade revelaram-se contrários à produção de uma cidade mais democrática e igualitária. Ainda de acordo com os autores:

Observa-se, sobretudo, um claro interesse em afastar e invisibilizar pobreza e conflitos das partes da cidade que deveriam ser positivadas, midiatizadas e vendidas como um projeto bem sucedido de cidade viável, criativa, com boa qualidade de vida e oposta às demais caóticas e desorganizadas metrópoles brasileiras. (CARVALHO; SUGAI, 2013, p. 4-5).

O referido Plano Diretor da cidade de Curitiba, que remodelaria a estrutura urbana da cidade nas décadas seguintes, foi promulgado em 1971, justamente no momento em que cresciam no país os estudos que viriam a ser conhecidos como uma teoria da urbanização na periferia do capitalismo. Tratam-se de estudos - influenciados pelo estruturalismo francês e seus teóricos que interpretaram a questão urbana, em especial Manuel Castells - desenvolvidos, principalmente, pelo Cebrap (Centro Brasileiro de Análise e Planejamento) e pela FAU-USP (Faculdade de Arquitetura e Urbanismo da Universidade de São Paulo) que procuraram analisar os efeitos do subdesenvolvimento na reprodução da força de trabalho - que se dá no espaço - a qual se dava de maneira bem diferente da que ocorria nos Estados de bem-estar social, gerando, consequentemente, uma urbanização também diferenciada.

O próprio termo "periferia" deve a estes pesquisadores a sua ampliação conceitual, uma vez que, de acordo com Arantes (2009), as definições de "periferia" - assim como as de "espoliação urbana" e "autoconstrução" da moradia - serão fundamentais para aclimatar os conceitos da sociologia francesa ao nosso contexto. Assim, aos poucos, a cidade passa de mero suporte de processos sociais e econômicos para ser compreendida - através de uma teoria crítica do urbano como parte importante da produção e reprodução do capital. De acordo com Arantes (2009):

Assim, será retomada e reavaliada a teoria da "renda da terra", em suas articulações com o Estado e o "capital da construção", e formulada a hipótese de um "padrão periférico de crescimento da metrópole". (ARANTES, 2009, p. 104).

De acordo com Arantes (2009), a conexão entre os referidos pesquisadores, formuladores de hipóteses para a interpretação da urbanização latino-americana, foi feita pelo sociólogo espanhol Manuel Castells - professor da Universidade de Paris e coordenador do Centro Interdisciplinar de 
Desenvolvimento Urbano e Regional de Santiago do Chile - que também foi o responsável pela organização do livro "Imperialismo e urbanização na América Latina", que, de acordo com Arantes (2009), tornou-se um marco para a nascente crítica marxista sobre a questão urbana, tendo como participantes quatro pesquisadores do Cebrap - Paul Singer, Fernando Henrique Cardoso, Lúcio Kowarick, Cândido Ferreira de Camargo -, além do geógrafo Milton Santos.

Entre os pesquisadores da FAU-SP, vale a pena destacar as contribuições de Ermínia Maricato, que é a organizadora do livro "A produção da casa (e da cidade) no Brasil industrial” (1979), produção com textos de 1975 a 1979, que representou um importante avanço em relação à produção do Cebrap, principalmente por ter melhor desenvolvido e aprofundado os conceitos de "periferia", "espoliação" e "autoconstrução". Além dela, Gabriel Bolaffi, sociólogo e professor da FAU, através de sua pesquisa sobre o Plano Nacional de Habitação - "Habitação e urbanismo: o problema e o falso problema" supera o conceito de periferia como lugar físico e como polo dual para caracterizar um movimento próprio do crescimento das cidades brasileiras, tomando São Paulo como seu exemplo mais predatório. De acordo com Bolaffi, as ações do BNH não devem ser entendidas como desvio de rota, mas como regra da própria dinâmica urbana, que ele passa a denominar "padrão periférico de crescimento da metrópole".

As principais críticas às análises de Castells - que irão influenciar a produção marxista sobre a questão urbana nos anos seguintes - referiam-se ao fato destas delimitarem a cidade como espaço exclusivo de consumo coletivo de serviços do Estado, deixando de lado questões consideradas vitais na sociedade como o consumo e a cultura de massas. Entre as produções do Cebrap desse período vale a pena destacar o livro do economista Paul Singer, "Economia política da urbanização" (1973), e "Crítica à razão dualista" (1972), do economista e sociólogo Francisco de Oliveira.

Frente aos objetivos do presente trabalho, as pesquisas do grupo que desenvolvia a pesquisa sobre cidade, cultura de massas e movimentos populares urbanos, coordenado pelos sociólogos Lúcio Kowarick, Vinicius Caldeira Brant e Cândido Procópio de Camargo, adquirem especial relevância pelo destaque dado à questão da periferização das metrópoles - em especial no livro "São Paulo 1975: crescimento e pobreza" (1976) - ainda que de forma descritiva e não analítica. De acordo com Arantes (2009):

É assim que surge o problema da "periferia": aglomerados, clandestinos ou não, carentes de infraestrutura, onde vai residir a mão de obra necessária para o crescimento da produção. A periferia, como lugar físico, é apresentada, por fim, como única categoria propriamente urbana do livro, e mesmo assim sob a forma descritiva em vez de analítica. Ela é a decorrência espacial do "espraiamento horizontal" da cidade (sem que este seja de fato explicado) e do "paradoxo da mobilidade". Segundo os autores, baseados em dados do Dieese, em 1958 o gasto em transporte representava $2,9 \%$ do salário e, em 1970, pulou para $11,5 \%$, fenômeno que é resultante de uma urbanização baseada na casa própria (em vez do aluguel), 
que tende a fixar o trabalhador no bairro, no mesmo momento em que ocorre a intensificação da mobilidade do emprego. Ou seja, a transformação do trabalhador em pequeno proprietário tornou-se fonte adicional de dificuldades de vida. (ARANTES, 2009, p. 116).

A parte analítica adquire relevo, principalmente, a partir do lançamento do livro de Lucio Kowarick, "A espoliação urbana" (1979), ou seja, a expulsão dos pobres para as periferias, característica do processo de urbanização no Brasil e decorrente da combinação de crescimento e pauperização.

Como procuramos demonstrar a seguir, a segregação socioespacial - analisada através do Índice de Bem-estar Urbano (Ibeu) e pela taxa de mobilidade urbana - além de revelar outro aspecto da desigualdade social em Curitiba, também demonstra a seletividade social das medidas de higiene e isolamento recomendadas pelas autoridades e consideradas essenciais no enfrentamento da pandemia de Covid-19. Seletividade que pode ser o gatilho de uma transmissão descontrolada caso não sejam desenvolvidas ações com foco nessas áreas com alto índice de vulnerabilidade social.

\section{Centro e periferia de Curitiba vistos pelo Índice de Bem-estar Urbano (Ibeu) e pela taxa de mobilidade urbana}

O Atlas da Vulnerabilidade Social nos Municípios Brasileiros (IPEA, 2015) já destacava a necessidade de um esforço para ampliar o entendimento das situações tradicionalmente definidas como de pobreza, buscando exprimir uma perspectiva ampliada complementar àquela atrelada à questão da insuficiência de renda.

De acordo com o estudo, tratam-se de noções, antes de tudo políticas, que introduzem novos recursos interpretativos sobre os processos de desenvolvimento social, para além de sua dimensão monetária. Nesse sentido, a leitura desses processos, resultante desta "nova" conceituação, pode dialogar e produzir efeitos sobre as propostas e os desenhos das políticas públicas, alargando seu escopo e colocando em evidência as responsabilidades do Estado, em todos os seus níveis administrativos, na promoção do bem-estar dos cidadãos (IPEA, 2015), especialmente em momentos de crise como a atual pandemia de Covid-19, que exige uma ampliação da cobertura estatal com vistas a evitar maiores danos econômicos e sociais.

Os bairros periféricos da cidade de Curitiba, aqui analisados, encontram-se bem distantes dos bairros da região central. De acordo com Firkowski e Moura (2014):

Apesar da expansão dispersa e fragmentada da aglomeração metropolitana, mesclando segmentos sociais por vezes antagônicos, a desigualdade segue sendo uma expressão marcante da RMC, refletindo o modelo de ocupação adotado, que 
induz à periferização da pobreza e ao abandono de grandes contingentes de população em áreas com baixas condições de bem-estar urbano. (FIRKOWSKI; MOURA, 2014, p. 36).

A caracterização dos bairros aqui empreendida se baseia no Índice de Bem-estar Urbano (Ibeu) global e local, desenvolvido pelo Observatório das Metrópoles. O Ibeu é composto por cinco dimensões: mobilidade urbana; condições ambientais urbanas; condições habitacionais urbanas; atendimento de serviços coletivos urbanos; e infraestrutura urbana.

O índice varia entre zero e um, quanto mais próximo de um, melhor é o bem-estar urbano, quanto mais próximo de zero, pior é o bem-estar urbano.

Cada uma dessas dimensões, assim como o índice geral, é constituída por um conjunto de indicadores, obtidos na base de dados do Censo Demográfico do Instituto Brasileiro de Geografia e Estatística (IBGE) de 2010, extraídos tanto da base do universo (questionário básico) e da base de microdados (questionário amostral) quanto da base do entorno dos domicílios, agregados no nível das áreas de ponderação. De acordo com Ribeiro e Ribeiro (2013):

trata-se de um índice que prioriza componentes de alcance coletivo e não individual, ou seja, aquilo que "a cidade deve proporcionar às pessoas em termos de condições materiais de vida”. (RIBEIRO; RIBEIRO, 2013, p. 9).

Ainda, de acordo com as autoras, o Ibeu:

procura avaliar a dimensão urbana do bem-estar usufruído pelos cidadãos brasileiros promovido pelo mercado, via o consumo mercantil, e pelos serviços sociais prestados pelo Estado. Tal dimensão está relacionada com as condições coletivas de vida promovidas pelo ambiente construído da cidade, nas escalas da habitação e da sua vizinhança próxima, e pelos equipamentos e serviços urbanos. (RIBEIRO; RIBEIRO, 2013, p. 7).

Com base no Índice de Bem-estar Urbano (Ibeu), conclui-se que os bairros da região periférica (localizados no sul e extremo sul do município) e os bairros da região central apresentam enormes diferenças nas principais dimensões analisadas, em especial as referentes às condições habitacionais urbanas, atendimento de serviços coletivos urbanos e infraestrutura urbana.

Todos os bairros da região central aqui analisados apresentam índices que variam de patamar médio de bem-estar urbano (de 0,701 a 0,800 ) a índices considerados ótimos (de 0,900 a 1,000).

No entanto, todos os bairros da região periférica apresentam índices abaixo de 0,700, ou seja, em patamares considerados ruins ou muito ruins de bem-estar urbano.

Em relação à Mobilidade Urbana, de acordo com o Ibeu, os bairros periféricos apresentaram índices considerados ruins ou muito ruins (de 0,001 a 0,500$)$ em contraste com os bairros da região central, que apresentaram de índice intermediário (de 0,701 a 0,800) a índices considerado ótimos, a maioria (sempre acima de 0,801 ). 
Assegurada através do Sistema de Transporte Coletivo ${ }^{4}$, a política de mobilidade urbana no município sempre acarretou um cerceamento do direito à cidade, ao não assegurar que a população tivesse acesso equitativo aos serviços públicos, uma vez que, quanto mais distante das regiões de infraestrutura consolidada (bairros da região central), menos opções de deslocamento, colocando em xeque o fato de o transporte ser um direito social dos brasileiros previsto na constituição.

A região periférica, aqui analisada, é a mais dependente do sistema de transporte coletivo e sempre sofreu as consequências da quantidade reduzida do número de ônibus e a consequente aglomeração, tanto em locais de embarque e desembarque quanto dentro dos veículos. São os bairros mais distantes dos equipamentos e bens públicos, além dos postos de trabalho, localizados, principalmente, na região central da cidade.

Em tempos de pandemia, essa aglomeração despertou o alerta das autoridades sanitárias pelo perigo de uma disseminação descontrolada do vírus. Tanto que no dia 20 de março de 2020, a Companhia de Urbanização de Curitiba (Urbs) determinou - alegando que, em função da redução de $37 \%$ na demanda de passageiros - que as linhas de reforço, que atendem pela manhã e à tarde, não iriam mais funcionar. Além disso, a previsão era de que a partir do dia 25, o sistema passasse a funcionar com a tabela de sábado durante os dias de semana e a de domingo nos fins de semana.

Não é de se espantar que a medida causou grande aglomeração nos terminais, tornando-se notícia nos principais meios de comunicação da cidade, o que levou o prefeito Rafael Greca (DEM) a não só cancelar a medida, como determinar a abertura de uma investigação sobre o ocorrido, como reportado pelo site de notícias Bem Paraná5: "É inaceitável que a população tenha que ser submetida a essa superlotação em um momento de pandemia de novo coronavírus. Vamos investigar", disse o prefeito.

Assim, considerando que as autoridades sanitárias são unânimes em destacar a importância de ações mais efetivas no enfrentamento da pandemia de Covid-19 direcionadas às populações mais vulneráveis, parece correta - e necessária - a estratégia adotada pela Secretaria Municipal de Saúde de Curitiba de priorizar a atenção básica nas áreas periféricas, como será analisado na próxima seção.

\footnotetext{
${ }^{4} \mathrm{O}$ sistema de transporte é gerenciado e fiscalizado por uma empresa prestadora de caráter misto, a Urbanização de Curitiba S.A. (Urbs), responsável pela contratação das empresas de ônibus e garante à população a prestação do serviço público de forma descentralizada. Na esfera metropolitana, a entidade que exerce o mesmo papel de gerenciamento e fiscalização é a Comec - Coordenação da Região Metropolitana de Curitiba. Atualmente, as linhas do sistema de transporte coletivo de Curitiba são caracterizadas e hierarquizadas de acordo com a sua função, denominadas como Expressas, Alimentadoras, Interbairros, Diretas, Troncais e Intermunicipais, compondo a RIT e as demais que não são integradas. Além disso, existem as linhas da RIT-M, que conectam os municípios metropolitanos entre si e Curitiba.

${ }^{5}$ Disponível em: https:/www.bemparana.com.br/noticia/greca-manda-investigar-responsabilidades-sobre-aglomeracaoem-terminais\#.Xq_DBahKjIU.
} 


\section{Estratégias de enfrentamento da Covid-19: impactos da segregação espacial na periferia de}

\section{Curitiba}

Autoridades sanitárias têm destacado a importância do Programa Saúde da Família ${ }^{6}$ (PSF) no enfrentamento da Covid-19. Curitiba aderiu ao PSF em 1995, em sintonia com a regulamentação do Sistema Único de Saúde (SUS). Existem, até o momento, dois modelos de US na Atenção Primária em Saúde (APS) em Curitiba. Um se refere ao das unidades da Estratégia Saúde da Família - ESF, e o outro, ao modelo tradicional de Unidade Básica de Saúde - UBS.

É importante destacar que desde julho de 2018, a Secretaria Municipal da Saúde (SMS) deu início a um processo de readequação da distribuição de profisssionais na rede de atenção básica com o alegado objetivo de corrigir distorções, priorizando as comunidades mais carentes e com maior necessidade de serviços da área. Para tanto, a SMS conduziu um amplo estudo com base no Índice de Vulnerabilidade das Áreas de Abrangência das Unidades Municipais de Saúde (Ivab) elaborado de acordo com o Índice de Vulnerabilidade das Famílias do Paraná (IVF-PR) do Instituto Paranaense de Desenvolvimento Econômico e Social (Ipardes) e da população do Censo do IBGE - 2010 por área de abrangência utilizando os dados do cadastro único do Governo Federal ${ }^{7}$. Desde então, o Ivab é utilizado como estratégia para a promoção da equidade no Sistema Único de Saúde em Curitiba, definindo a distribuição dos recursos do SUS Curitiba e norteando as ações de saúde no município.

O Índice de Vulnerabilidade das Áreas de Abrangência das Unidades Municipais de Saúde Ivab surgiu através da aprovação do Decreto nº 638, de 21 de junho de 2018. O Ivab é calculado pela média aritmética entre os índices de 4 dimensões:

I - Adequação do domicílio - composto por 5 componentes: espécie de domicílios, densidades por dormitório, material de construção do domicílio, água encanada, esgotamento sanitário;

II - Perfil e composição familiar - composto por 9 componentes: responsabilidade pela família, razão entre crianças e adolescentes, e adultos, presença de trabalho infantil na família, presença de crianças e adolescentes internados, presença de adultos internados, presença de idosos internados, presença de pessoas com deficiência na família, idosos em condição de agregado, analfabetismo do chefe de família;

III - Acesso ao trabalho e renda - composto por 2 componentes: trabalho dos adultos, renda familiar mensal per capita;

\footnotetext{
${ }^{6}$ A Estratégia de Saúde da Família (ESF) iniciou com o Programa Saúde da Família (PSF), concebido pelo Ministério da Saúde em 1994. Desde então é definido como estratégia prioritária para a organização e fortalecimento da Atenção Primária em Saúde (APS) no país. Por meio dessa estratégia, a atenção à saúde é feita por uma equipe composta por profissionais de diferentes categorias (multidisciplinar) trabalhando de forma articulada (interdisciplinar) que considera as pessoas como um todo, levando em conta suas condições de trabalho, de moradia, suas relações com a família e com a comunidade.

${ }^{7}$ O Cadastro Único é um conjunto de informações sobre as famílias brasileiras em situação de pobreza e extrema pobreza. Essas informações são utilizadas pelo Governo Federal, pelos Estados e pelos municípios para implementação de políticas públicas com o alegado objetivo de promover a melhoria da vida dessas famílias.
} 
IV - Condições de escolaridade - composto por 3 componentes: crianças e adolescentes fora da escola, defasagem idade/série, jovens e adultos sem ensino fundamental. (CURITIBA, Decreto $n^{\circ} 638,2018$ ).

A partir do Ivab, as Unidades Municipais de Saúde são ranqueadas sob a lógica de intervalos regulares com base no conjunto de dados ordenados de forma crescente, e divididas em três grupos a partir do cálculo dos tercis. As Unidades Municipais de Saúde localizadas no tercil 1 são denominadas como de baixa vulnerabilidade, no tercil 2 como de média vulnerabilidade e no tercil 3 como de alta vulnerabilidade. De acordo com o Decreto ${ }^{\circ} 638$, os intervalos de Ivab para cada tercil são:

I - Tercil 1 (baixa vulnerabilidade): Unidades de saúde com percentagem menor que $3,91 \%$;

II - Tercil 2 (média vulnerabilidade): Unidades de saúde com percentagem maior ou igual a $3,91 \%$ e menor que $7,80 \%$;

III - Tercil 3 (alta vulnerabilidade): Unidades de saúde com percentagem maior ou igual a $7,80 \%$ até o limite superior, que pode atingir $100 \%$. (CURITIBA, Decreto ${ }^{\circ}$ $638,2018)$.

Compreender os impactos da desigualdade gerada pela segregação socioespacial em Curitiba é um dos objetivos do grupo de pesquisa "Políticas sociais: análise comparada das experiências brasileiras", do Programa de Pós-graduação em Sociologia da Universidade Federal do Paraná (UFPR). Procurando dar conta desse objetivo - a exemplo de outros programas de pós-graduação, que, em meio à atual conjuntura de isolamento social, têm divulgado boletins informativos focados nas estratégias de enfrentamento da pandemia - foi publicado pelo autor dois boletins: o primeiro, no sítio do Observatório das Metrópoles, intitulado "O Índice de Vulnerabilidade das Unidades Municipais de Saúde como estratégia de enfrentamento da Covid-19 na periferia de Curitiba"8, e o segundo, intitulado "O Programa Saúde da Família como estratégia de enfrentamento da Covid-19 na periferia de Curitiba"”, publicado pela Associação Nacional de Pós-graduação em Ciências Sociais (Anpocs).

A Figura 1, que integra o estudo apresentado nos respectivos boletins, apresenta o mapa com a distribuição das unidades de saúde de acordo com o Índice de Vulnerabilidade das Áreas de Abrangência das Unidades Municipais de Saúde (Ivab).

\footnotetext{
${ }^{8}$ Disponível em: https://www.observatoriodasmetropoles.net.br/o-indice-de-vulnerabilidade-das-unidades-municipaisde-saude-como-estrategia-de-enfrentamento-da-covid-19-na-periferia-de-curitiba/.

${ }_{9}^{9}$ Disponível em: http://anpocs.org/index.php/publicacoes-sp-2056165036/boletim-cientistas-sociais/2385-boletim-n59-cientistas-sociais-e-o-coronavirus.
} 
FIGURA 1 - DISTRIBUIÇÃO DAS UNIDADES DE SAÚDE DE ACORDO COM O ÍNDICE DE VULNERABILIDADE DAS ÁREAS DE ABRANGÊNCIA DAS UNIDADES MUNICIPAIS DE SAÚDE (IVAB)

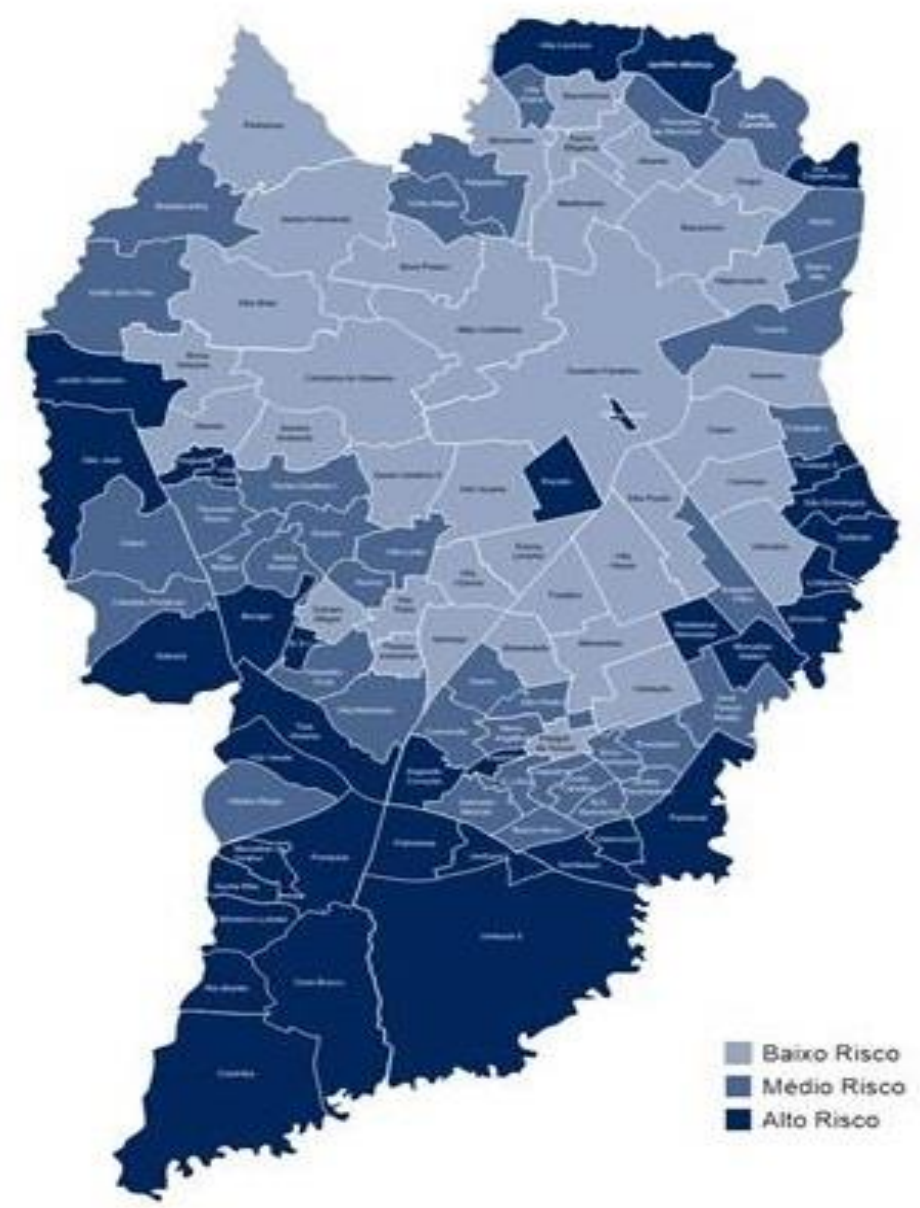

FONTE: SECRETARIA MUNICIPAL DE SAÚDE DE CURITIBA (2018).

Como se pode notar, todos os bairros da região periférica de Curitiba analisados no presente estudo estão localizados em áreas consideradas de alto risco, em contraste com as unidades de saúde melhor avaliadas pelo Ivab, e que se encontram nos bairros da região central, todas com baixa vulnerabilidade (unidades de saúde com percentagem menor que 3,91\%).

Assim, considerando que as autoridades sanitárias são unânimes em destacar a importância do Programa Saúde da Família (PSF) no enfrentamento da pandemia de Covid-19 - programa cuja gênese se insere num contexto mais amplo de estudos e pesquisas que associam a organização social do território às inúmeras formas de desigualdade - a estratégia adotada pela Secretaria Municipal de Saúde de Curitiba, de transferir profissionais do PSF para áreas com maior vulnerabilidade social, iniciada em 2018, antes, portanto, do início da pandemia de Covid-19, vai ao encontro das recomendações nacionais e internacionais que têm alertado para a seletividade social das medidas recomendadas de higiene e isolamento diante da realidade dos territórios periféricos urbanos, espaços 
com maior propensão à disseminação do novo coronavírus. No entanto, é uma estratégia que pode ser impactada negativamente pela política de mobilidade urbana em casos mais graves da doença.

A esse respeito, em abril de 2020 o Ipea lançou a Nota Técnica "Mobilidade urbana e o acesso ao Sistema Único de Saúde para casos suspeitos e graves de Covid-19 nas vinte maiores cidades do Brasil", elaborada por Pereira et al, na qual foram estimadas quantas são e onde moram as pessoas mais vulneráveis (baixa renda e acima de 50 anos de idade).

A Figura 2 apresenta esse recorte para a cidade de Curitiba, sendo: A) a população de baixa renda acima de 50 anos de idade que não conseguiria acessar a pé, em menos de trinta minutos pelo menos, um estabelecimento que atende pelo SUS e que poderia fazer triagem e encaminhamento de pacientes suspeitos de Covid-19; e B) a população que mora a uma distância maior do que 5 km de um hospital com capacidade de internar pacientes em estado grave de insuficiência respiratória.

FIGURA 2 - ACESSO DA POPULAÇÃO A ESTABELECIMENTOS DE SAÚDE EM CURITIBA (2020)

A) 5.1 mil pessoas

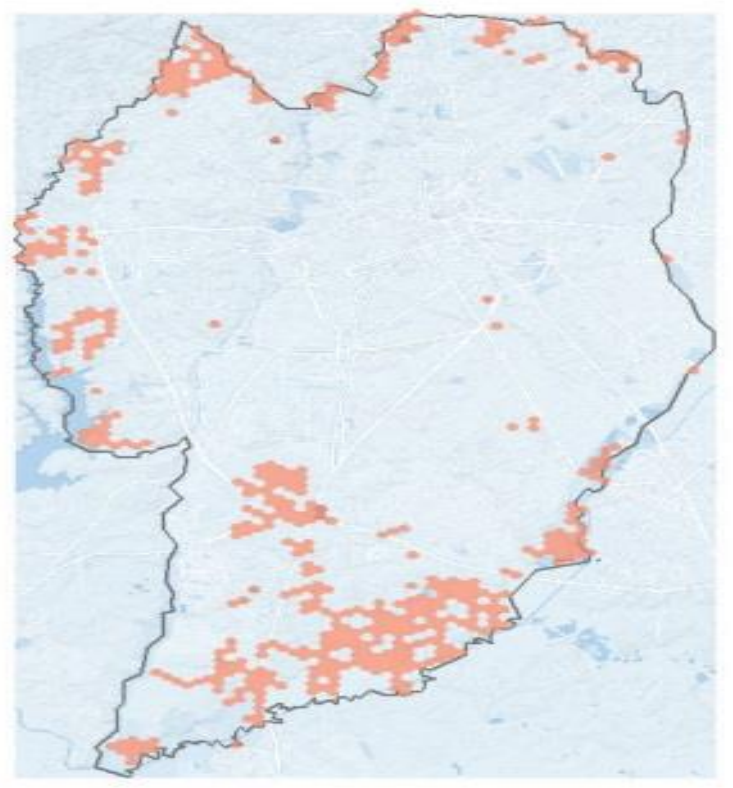

B) 116,4 mil pessoas

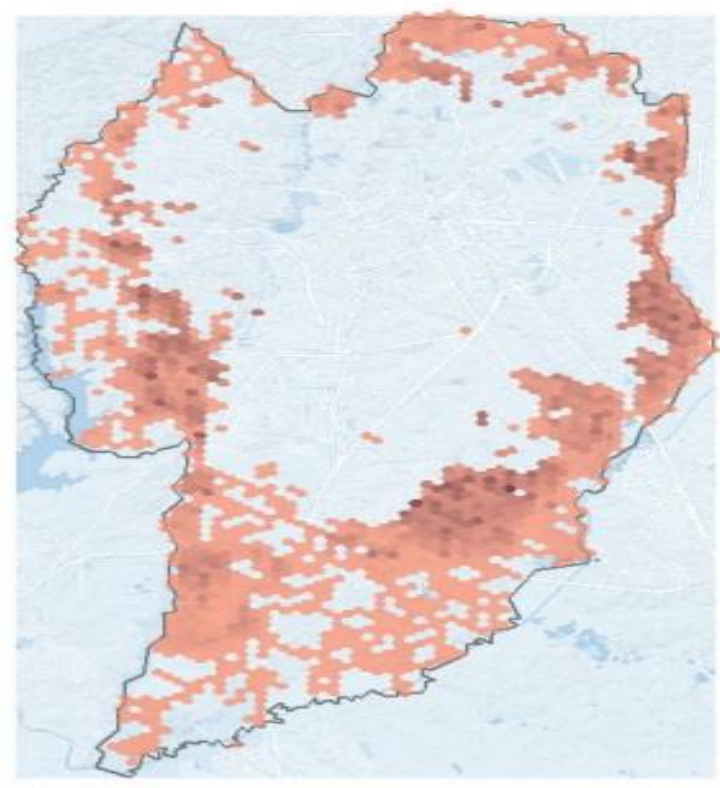

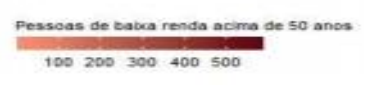

FONTE: IPEA (2020).

A nota também avaliou a capacidade de atendimento do SUS da demanda por internação em UTI de pacientes em estado grave, com casos suspeitos ou confirmados de Covid-19.

A Figura 3 apresenta a razão entre o número de leitos de UTI adulto com respirador disponíveis no SUS para 10 mil habitantes na zona de captação de cada hospital, sendo que cada hospital é representado por um círculo, cujo tamanho reflete a razão entre o número de leitos/respiradores daquele hospital e o tamanho da população em sua área de influência. 
FIGURA 3 - RAZÃO ENTRE O NÚMERO DE LEITOS DE UTI ADULTO COM RESPIRADOR DISPONÍVEL NO SUS PARA 10 MIL HABITANTES NA ZONA DE CAPTAÇÃO DE CADA HOSPITAL - CURITIBA (2020)

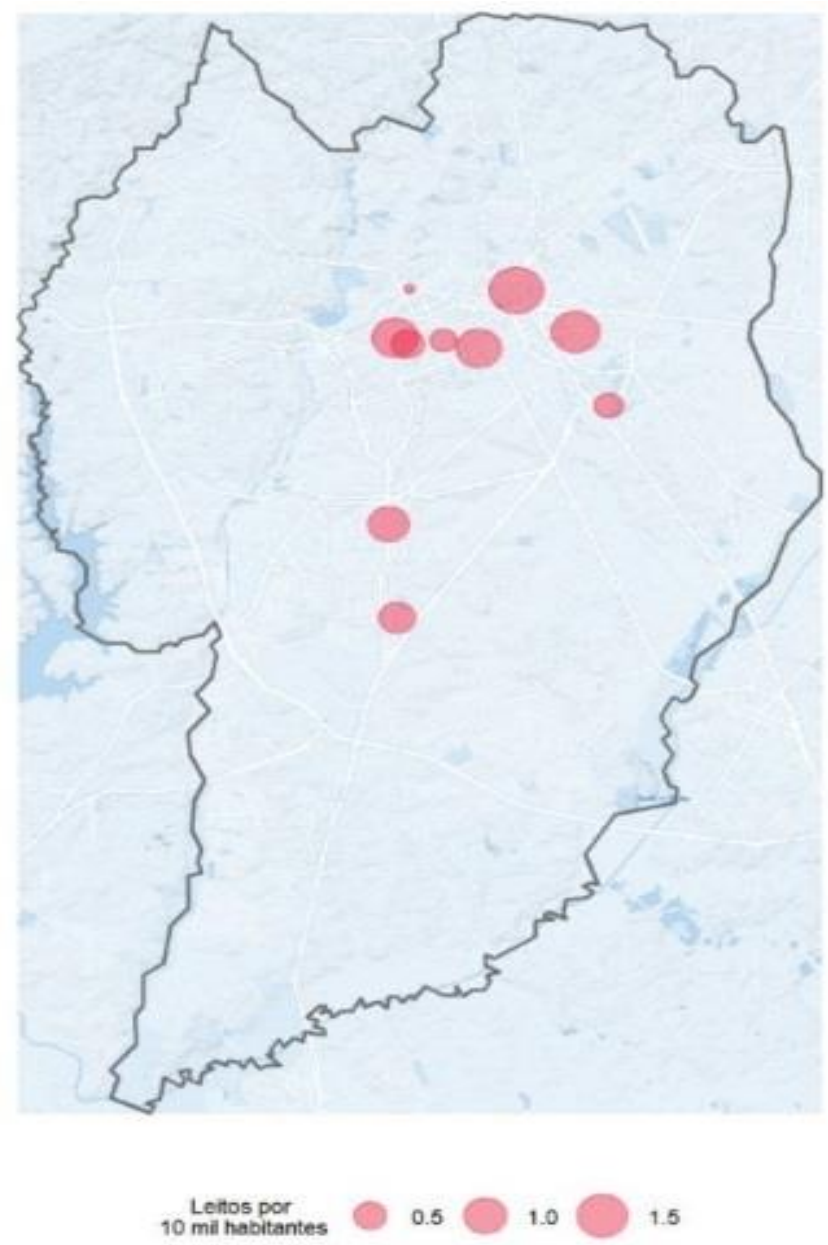

FONTE: IPEA (2020).

Curitiba segue o padrão observado em outras cidades como Porto Alegre, Rio de Janeiro, São Paulo, Maceió, Goiânia, Brasília e Belém, ou seja, concentra um maior número de hospitais com mais leitos por habitante na região central. A disponibilidade de leitos de UTI e respiradores para atender a pacientes em estado grave com suspeita de Covid-19 tende a ser consideravelmente menor nas periferias dessas cidades.

Um eventual, e previsível, aumento do número de casos de Covid-19 nestas periferias - devido a outras situações de vulnerabilidade social, como condições precárias de moradia, o acesso restrito ou inexistente de serviços de abastecimento de água e esgoto, entre outros - poderia fazer delas o foco de uma transmissão descontrolada. E, nesse sentido, a relação entre a distância entre esses bairros periféricos e os estabelecimentos com capacidade para atender os casos mais graves de Covid-19, 
agravada pela baixa taxa de mobilidade urbana, ocasionada pelo baixo número de ônibus disponíveis, é mais um indicativo da seletividade social das medidas adotadas pelo Estado.

\section{Considerações finais}

O Atlas da Vulnerabilidade Social nos Municípios Brasileiros (IPEA, 2015) já destacava a necessidade de um esforço para ampliar o entendimento das situações tradicionalmente definidas como de pobreza, buscando exprimir uma perspectiva ampliada complementar àquela atrelada à questão da insuficiência de renda. Nesse sentido, a leitura desses processos, resultante dessa "nova" conceituação - nos quais se incluem os demais índices utilizados, como o Índice de Bem-estar Urbano (Ibeu) e o Índice de Vulnerabilidade das Áreas de Abrangência das Unidades Municipais de Saúde (Ivab) - pode dialogar e produzir efeitos sobre as propostas e os desenhos das políticas públicas, alargando seu escopo e colocando em evidência as responsabilidades do Estado, em todos os seus níveis administrativos, na promoção do bem-estar dos cidadãos. Tratam-se de estudos que adquirem especial relevância diante da atual pandemia de Covid-19 e dos esforços das autoridades sanitárias para evitar o aumento no número de casos da doença em diversos países do mundo.

Como procuramos demonstrar no presente trabalho, os bairros periféricos aqui analisados encontram grandes dificuldades em função desse contexto de segregação espacial, evidenciando a necessidade de o Estado - principal provedor dos bens e serviços - estabelecer uma política mais efetiva de democratização desses bens e serviços, visando romper com as fortes desigualdades que marcam esses territórios vulneráveis.

Assim, a estratégia da Secretaria Municipal de Saúde de Curitiba de readequar - com base no Ivab - a distribuição de profissionais na rede de atenção básica, priorizando as comunidades com maior necessidade de serviços da área, atende às recomendações das autoridades sanitárias no tocante ao enfrentamento da atual pandemia de Covid-19, pois as fortes desigualdades que marcam os territórios vulneráveis demandam políticas específicas, uma vez que a garantia legal de um direito universal (como a saúde) não tem se efetivado através de políticas universalistas que, muitas vezes, promovem uma distribuição equânime de recursos a grupos, territórios e regiões com recursos diferentes.

No entanto, como procuramos demonstrar, a eficácia dessa estratégia pode ser impactada negativamente caso não esteja articulada a outras políticas públicas, como as relativas à mobilidade urbana, por exemplo, uma vez que a população dos bairros periféricos aqui analisados é extremamente dependente do serviço de transporte coletivo. E, embora a redução dos serviços de 
transporte público promova uma diminuição dos níveis de mobilidade urbana, limitando a disseminação do vírus, ela revelou-se como potencial catalisadora de uma disseminação descontrolada do vírus, por promover aglomerações em terminais e veículos, justamente nas regiões mais afastadas dos estabelecimentos com capacidade para atender os casos mais graves de Covid-19. Assim, acreditamos que a seletividade social das medidas de contenção da pandemia não será resolvida sem um conjunto de políticas públicas articuladas que levem em consideração a realidade concreta dessas periferias.

\section{Referências}

ALBUQUERQUE, Al. A questão habitacional em Curitiba: o enigma da "cidade modelo". Dissertação de Mestrado. FAU-USP, São Paulo, 2007.

ARANTES, P. F. Em busca do urbano: marxistas e a cidade de São Paulo nos anos de 1970. Revista Novos Estudos Cebrap, n. 83, p. 103-127, 2009.

BRASIL. Ministério da Saúde. O SUS de A a Z: garantindo saúde nos municípios. 3. ed. Brasília: Ministério da Saúde, 2009. 480 p.

CARVALHO, A. S.; SUGAI, M. I. A produção da cidade segregada: o caso de Curitiba. In: II II Simpósio de Estudos Urbanos: a dinâmica das cidades e a produção do espaço. Campo Mourão: FECILCAM, 2013.

CURITIBA. Diário Oficial Eletrônico. Atos do Município de Curitiba. Decreto $\mathbf{n}^{\mathbf{0}} \mathbf{6 3 8}$, de 21 de junho de 2018. Institui o Índice de Vulnerabilidade das Áreas de Abrangência das Unidades Municipais de Saúde - IVAB. 2018.

FIRKOWSKI, O. L. C. F.; SILVA, M. N.; NAGAMINE, L. Y.; MOURA, R.; DELGADO, P. R. Uma leitura do Índice de Bem-estar Urbano na Região Metropolitana de Curitiba. In: FIRKOWSKI, O. L. C. F., MOURA, R. Curitiba: transformações na ordem urbana. Rio de Janeiro: Letra Capital; Observatório das Metrópoles, 2014.

IPARDES. Nota Técnica Índice de Vulnerabilidade das Famílias Paranaenses: mensuração a partir do Cadastro Único para Programas Sociais - Cadúnico. 2012.

IPEA. Atlas da Vulnerabilidade Social. Ipea, 2015. Disponível em: http://ivs.ipea.gov.br/index.php/pt/. Acesso em: 12 jul. 2019.

LOJKINE, J. O Estado capitalista e a questão urbana. São Paulo: Martins Fontes, 1997.

PEREIRA, R. H. M.; BRAGA, C. K. V.; SERVO, L. M.; SERRA, B.; AMARAL, P.; GOUVEIA, N. (2020). Mobilidade urbana e o acesso ao Sistema Único de Saúde para casos suspeitos e graves de COVID-19 nas 20 maiores cidades do Brasil. Nota Técnica N.14. Instituto de Pesquisa Econômica Aplicada (Ipea). Disponível em:

https://www.ipea.gov.br/portal/index.php?option $=$ com content\&view $=$ article \&id=35442\&Itemid=7 Acesso em: mai. 2020. 
RIBEIRO, L. C. de Q.; RIBEIRO, M. G. (Orgs.). Ibeu: Índice de Bem-estar Urbano. Rio de Janeiro: Letra Capital, 2013, 264 p. Disponível em: http://www.observatoriodasmetropoles.net/images/abook_file/ibeu_livro. pdf. Acesso em: out. 2019.

Artigo recebido em 11/05/2020. Aceito para publicação em 15/07/2020. 